\title{
Libras na Graduação Médica: o Despertar para uma Nova Língua
}

\author{
Libras in Medical Graduation: the Awakening \\ to a New Language.
}

Danielle de Azevedo Levino Emyle Brito de Souzal

Pedro Capela Cardoso

Anderson Carvalho da Silva

Adriana Edelves Trindade Martins Carvalho ${ }^{l}$

\section{PALAVRAS-CHAVE: \\ - Linguagem de Sinais; \\ - Surdez; \\ - Relações Médico-Paciente; \\ - Acesso aos Serviços de Saúde; \\ - Comunicação.}

\section{KEYWORDS:}

- Sign Language;

- Deafness;

- Doctor-Patient Relations;

- Health Services Accessibility;

- Communication.

Recebido em: 29/11/2012

Aprovado em: 26/02/2013

REVISTA BRASILEIRA DE EDUCAÇ̄̃o MÉDICA $291 \frac{37(2): 291-297 ; 2013}{2}$

\section{RESUMO}

Mais de 200 idiomas são falados no Brasil e, apesar do domínio da língua portuguesa, esta não é capaz de abarcar todas as necessidades de expressão da sociedade pluricultural brasileira. Assim, outras formas linguísticas surgiram para representar diferentes grupos sociais, como a língua brasileira de sinais (libras), utilizada pelos surdos. Diferentemente de mímica, a libras constitui um sistema linguístico de natureza gestual-visual, com estrutura gramatical própria. No contexto em que muito se discute acessibilidade, torna-se importante difundir conhecimentos sobre libras entre discentes de cursos de saúde, para contribuir na formação de profissionais habilitados a compreender e auxiliar as necessidades das pessoas que a utilizam como sua primeira lingua. Assim, este trabalho busca relatar a experiência vivenciada com o minicurso de libras ministrado aos discentes dos cursos de saúde da Universidade Federal do Tocantins (UFT) e divulgar os resultados colhidos como frutos da oficina que almejou diminuir a desinformação provocada pela barreira linguística e cultural existente entre ouvintes e surdos, proporcionando aos acadêmicos noções elementares que permitam melhorias nas futuras relações médico-paciente estabelecidas entre esses dois grupos.

\section{ABSTRACT}

More than 200 languages are spoken in Brazil and, despite the domination of Portuguese, this language is unable to meet all the expressive needs of the multicultural society of Brazil. Thus other linguistic forms have arisen to represent different social groups such as Brazilian Sign Language (LIBRAS) - used by deaf communities of urban Brazil. Unlike mime, LIBRAS is a linguistic system of a visual-gestural nature with its own grammatical structure. In a world where accessibility is increasingly discussed, it is important to disseminate knowledge about LIBRAS among students of health education courses to train qualified professionals in understanding and helping those who use it as their first language. This study highlights the experience of medicine students from the Federal University of Tocantins (UFT) who took a part time course in LIBRAS. This article also aims to diffuse the results of workshop aimed at reducing misinformation caused by the linguistic and cultural barrier existing between the deaf and hearers. Learners are thus provided with basic knowledge that will enable improved relationships between doctors and deaf patients. 


\section{INTRODUÇÃO}

Atualmente, mais de 200 idiomas são falados no Brasil, com línguas autóctones indígenas ou alóctones advindas de comunidades imigrantes e, apesar dessa variedade linguística, a língua portuguesa prevaleceu sobre as outras ${ }^{1}$. O monolinguismo nacional não contempla todas as necessidades de expressão de uma sociedade pluricultural como a brasileira e, assim, outras formas linguísticas surgiram para representar diferentes grupos sociais, como a língua brasileira de sinais (libras), utilizada pelas comunidades surdas urbanas brasileiras. Há também registros de outra língua de sinais utilizada pelos índios urubus-kaapor na floresta Amazônica².

O obstáculo da deficiência auditiva impeliu os surdos a compreender e interagir com o mundo por meio de experiências visuais, culminando com o desenvolvimento de uma cultura própria manifestada principalmente pelo uso de uma língua gestual-visual, a libras. Diferentemente da mímica, a libras constitui uma língua natural, com estrutura gramatical própria em seus níveis fonológico, morfológico, sintático, semântico, capaz de transmitir conceitos concretos e abstratos por meio de canal essencialmente visual ${ }^{2,3,4,5}$.

Devido à sua importância para o país, foram sancionadas a Lei $\mathrm{n}^{\mathrm{o}}$ 10.436, de 24 de abril de 2002, que reconhece oficialmente a libras como meio legal de comunicação e expressão ${ }^{6}$,e o decreto 5.626 de 2005, que, além de regulamentar a lei supracitada, determina a obrigatoriedade do ensino da libras nos cursos de formação para o exercício do magistério ou licenciatura nas diferentes áreas do conhecimento, seja de nível médio ou superior, sob diferentes esferas gestoras (federal, estadual ou municipal). Aos demais cursos de educação superior e profissional, o decreto afirma que a disciplina também deverá ser ofertada de forma eletiva ${ }^{7}$. Tais referências legais favorecem a inclusão social dos surdos e contribuem para a garantia de seus direitos como cidadãos brasileiros.

Conforme dados do Censo brasileiro de $2000,14,5 \%$ da população, o correspondente a 24,6 milhões de pessoas, era portadora de algum tipo de deficiência (dificuldade em enxergar, ouvir, locomover-se ou outra deficiência física ou mental). Os deficientes auditivos, sejam os incapazes de ouvir ou aqueles com alguma ou grande dificuldade permanente de ouvir, representavam $16,7 \%$, o equivalente a 5.735 .099 pessoas $^{8}$. O censo de 2010 revela que $24 \%$ da população, cerca de 45,6 milhões de brasileiros, majoritariamente mulheres, possui ao menos uma das deficiências mental, motora, visual e auditiva. Os deficientes auditivos somaram 9,7 milhões de pessoas, cuja distribuição entre os sexos corresponde a 5,3\% dos homens e 4,9\% das mulheres brasileiras. O documento ainda afirma a permanência das desigualdades em relação aos deficientes, que têm taxas de escolarização, ocupação e rendimento menores que a população sem nenhuma das deficiências investigadas ${ }^{9}$.

No contexto em que muito se discute acessibilidade, torna-se importante difundir conhecimentos sobre a libras entre discentes de cursos de saúde, para contribuir na formação de profissionais habilitados a compreender e auxiliar as necessidades das pessoas que a utilizam como sua primeira língua.

\section{OBJETIVOS}

- Relatar a experiência vivenciada com o minicurso de libras ministrado aos discentes dos cursos de saúde da Universidade Federal do Tocantins (UFT) e divulgar os resultados colhidos como frutos dessa oficina.

- Diminuir a desinformação provocada pela barreira linguística e cultural existente entre ouvintes e surdos de forma a proporcionar aos acadêmicos noções elementares que permitam melhorias nas futuras relações médico-paciente estabelecidas entre eles e pacientes surdos.

- Promover a ampliação do acesso de portadores de deficiência auditiva aos serviços de saúde por intermédio de profissionais capazes de estabelecer comunicação e compreender a necessidade desses pacientes além do previsto no modelo biomédico.

\section{METODOLOGIA}

Durante as atividades da IV Semana Acadêmica de Medicina, promovida pelos alunos do Curso de Medicina da UFT em novembro de 2011, foi ofertado o minicurso de libras em parceria com o Núcleo de Inclusão e Acessibilidade do Deficiente (NIAD) da universidade. A semana acadêmica é um evento de periodicidade anual, que tem por objetivo despertar nos discentes posturas relacionadas ao aprimoramento do conhecimento profissional, científico, tecnológico, artístico e cultural e, ainda, habilidades relativas à organização de tais atividades ${ }^{10}$.

Para avaliar o impacto do minicurso foi executado um pré-teste, no qual os participantes descreveram seus conhecimentos prévios sobre o surdo e a libras. Ao final das exposições, o pós-teste foi composto pela redação da contribuição dos conhecimentos adquiridos pelos discentes.

A interpretação de uma música na língua dos sinais marcou o começo das atividades e destacou a importância dos sinais acompanhados da expressão corporal e demais componentes inerentes à libras, indispensáveis ao estabelecimento da comunicação. Na oportunidade, buscou-se apresentar aos participantes conceitos sobre a surdez e o surdo; a expressão clínica e cultural da surdez; a realidade da comunidade surda na região; as implicações práticas do uso de libras no cotidiano médico e conhecimentos básicos para a compreensão da 
língua de sinais, com vistas a um adequado atendimento ao paciente surdo.

Os tópicos seguintes trarão uma discussão acerca dos temas apresentados no minicurso, norteadores dos saberes transmitidos.

\section{O SURDO E A SURDEZ}

A surdez se caracteriza pela diminuição da acuidade e percepção auditivas que dificultam a aquisição da linguagem oral de forma natural ${ }^{3}$. À luz da medicina, surdez é entendida como a perda da sensibilidade auditiva com redução da percepção sonora e pode ser classificada em dois grandes grupos: de condução e neurossensorial. A surdez de condução, menos comum, afeta o ouvido externo ou médio e acontece quando as ondas do fenômeno acústico não são bem conduzidas para o ouvido interno. A surdez neurossensorial é aquela que ocorre quando a cóclea não consegue converter a energia mecânica da vibração do som em energia elétrica para transmiti-la ao cérebro ${ }^{11}$.

Qualquer alteração ou distúrbio no processamento normal da audição, independentemente da sua causa, tipo ou grau de severidade, constitui uma alteração auditiva ${ }^{12}$. A modificação da audição pode ser congênita ou adquirida, com diferentes implicações para o paciente. Quando o indivíduo nasce surdo, a surdez é pré-lingual, iniciada antes da aquisição da linguagem oral, quando acomete o indivíduo no decorrer de sua vida, pode ser pré ou pós-lingual, se advier antes ou depois da aquisição da oralidade ${ }^{12}$. Surdez pré-lingual inclina seus portadores a adotar a linguagem de sinais como primeira

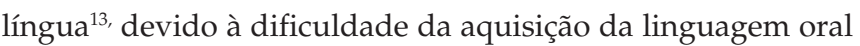
de forma natural.

Diversas causas podem contribuir para acarretar a surdez, sejam elas pré-natais, como fatores genéticos, doenças infectocontagiosas (rubéola) e exposição a substâncias ototóxicas; perinatais, devido a parto prematuro, anoxia cerebral, traumas de parto; ou pós-natais, por doenças infectocontagiosas (meningite, rubéola, caxumba), exposição a substâncias ototóxicas, problemas metabólicos (diabetes), tumores, acidentes ou avanço da idade ${ }^{11,12}$.

O comprometimento da audição - ou deficiência auditiva - caracterizado pela perda total ou parcial da capacidade de ouvir, pode ser graduado de leve (16 a $40 \mathrm{~dB})$ a profundo (acima de $91 \mathrm{~dB}$ ), conforme verificação por audiômetro, uni ou bilateralmente. Considera-se deficiência auditiva a perda bilateral, parcial ou total, de $41 \mathrm{~dB}$ ou mais, aferida por audiograma em diferentes frequências ${ }^{7,14}$.

O surdo é o sujeito que se identifica enquanto tal, apreende o mundo por meio de experiências visuais e tem o direito e a possibilidade de apropriar-se da língua de sinais e da língua oficial do país ${ }^{3}$. A legislação brasileira considera pessoa surda aquela que, por ter perda auditiva, compreende e interage com o mundo por meio de experiências visuais, manifestando sua cultura principalmente pelo uso da libras ${ }^{7}$.

Dessa forma, diferenciam-se adequadamente sujeitos não ouvintes dos indivíduos surdos, conceitos de grande relevância para a compreensão da complexidade do universo da disfunção auditiva.

\section{CULTURA E COMUNIDADE SURDA}

Cultura pode ser encarada como medidor simbólico que torna a vida em comunidade possível. Por essa perspectiva, se expressa através de linguagem, juízos de valor, arte, motivações, gerando a ordem do grupo, com a criação de códigos, formas de organização e representação ${ }^{15}$. Logo, a cultura surda é resultado das interações dos surdos com o meio em que vivem, os jeitos de interpretar o mundo, de viver nele, e constitui um complexo campo de produções culturais: língua de sinais, identidades, pedagogia, política, leis, artes, etc. ${ }^{16}$

$\mathrm{O}$ conceito de comunidade remete à ideia de indivíduos que participam e compartilham dos mesmos interesses em uma determinada localização. Extensivamente à comunidade surda, tais pessoas não necessariamente são surdas, pois envolve sujeitos ouvintes - membros da família, intérpretes, professores e amigos ${ }^{2,17}$.

$\mathrm{O}$ fato de uma pessoa ser surda não equivale a dizer que ela faça parte de uma cultura e uma comunidade surdas. A distinção entre ser surdo e ser deficiente auditivo está na atuação política e social desempenhada pelo indivíduo. Uma pessoa surda que luta por seus direitos políticos, linguísticos e culturais faz parte de uma comunidade surda ${ }^{2}$.

Profissionais da saúde capazes de estabelecer comunicação, vínculo e adequada assistência à pessoa surda também são participantes dessa comunidade. Suas ações serão ainda mais diferenciadas quando estiverem imbuídos da compreensão da identidade da pessoa surda, dos fatores culturais que caracterizam a sua comunidade e dos instrumentos legais que norteiam as relações entre eles e tais pacientes ${ }^{18}$.

\section{MODALIDADE LINGUÍSTICA}

A libras é uma língua espaço-visual natural, originando-se da integração entre pessoas surdas e possui níveis linguísticos estabelecidos: fonológico, morfológico, sintático, semântico e pragmático ${ }^{2,3,4,5}$, sendo, portanto, adequada para transmitir informações e para ensinar.

A analogia com a linguagem oral permite melhor compreensão: os fonemas são as menores unidades da língua, que, 
em combinação, originam as palavras; os queremas (cheremas, do grego cher, palavra que significa "mão"), detêm o mesmo valor para a libras na formação dos sinais ${ }^{19}$, estes últimos se assemelham às palavras. Tais sinais não podem ser interpretados isoladamente, e sim no contexto de seus mais diversos parâmetros de componentes manuais ou não manuais. A configuração de mãos (posição das mãos), pontos de articulação (local que as mãos ocuparão), movimento, orientação/direcionalidade retratam os componentes manuais e as expressões facial e corporal, os não manuais s,3,4,5. $^{2}$.

As configurações das mãos são as formas adotadas pelas mãos dominantes para a formação do sinal e podem ser aquelas utilizadas para representar as letras (grafemas) na datilologia, ou outras feitas por uma ou pelas duas mãos do emissor ou sinalizador ${ }^{2}$, podem ainda conferir flexão de gênero e número. Existem 64 configurações de mãos das quais o alfabeto manual utiliza apenas 26 para representar as letras ${ }^{2,5}$

O ponto de articulação é o lugar que a mão dominante configurada ocupa ou toca. Pode-se tocar alguma parte do corpo ou ocupar o espaço neutro, seja ele vertical (do tronco à cabeça) ou horizontal (à frente do emissor ${ }^{2,3}$, também pode corresponder à flexão de lugar.

Os sinais podem ou não se deslocar no espaço, isto é, ter movimento e direção/orientação ${ }^{2}$. Tais parâmetros podem representar a flexão para processo/tempo e pessoa do discurso, respectivamente.

As expressões facial e corporal atribuem aos sinais uma entonação, uma intensidade, ou ainda determinam se a frase é interrogativa, exclamativa, negativa ou afirmativa, atuação semelhante aos advérbios modais e intensificadores ${ }^{3,4,5}$.

Por exemplo: para podermos dizer: "Qual seu nome?" e "Prazer conhecê-lo" em libras, são necessários:

- sinais NOME e SEU, somados à expressão facial de interrogação ou apenas o sinal NOME e a expressão facial de interrogação.

O sinal NOME é formado com a mão dominante em letra [U] do alfabeto manual, no espaço neutro vertical, movimentando da esquerda para a direita (se mão dominante for esta última). O sinal SEU é formado com a mão dominante com configuração de numeral um, com o dedo indicador na horizontal, apontando para frente. A expressão facial de dúvida/ questionamento acompanha os sinais.

- sinais PRAZER e CONHECER e expressão facial de alegria, felicidade.

O sinal PRAZER é composto pela mão dominante aberta, com a palma virada para o tórax, movimentando-se em sentido horário no espaço neutro vertical. O sinal CONHECER é formado pela mão dominante com configuração de letra [B] do alfabeto manual, tocando o queixo com o dedo indicador e a palma da mão voltada para o lado oposto ao dominante.

Percebe-se que foram utilizados diferentes sinais, cada um com seus parâmetros adequados à emissão da mensagem desejada. Nota-se que nem toda palavra oral necessita de sinal e nem todo sinal representa uma palavra e, ainda, que os elementos conectivos (artigos, preposições, conjunções) estão incorporados aos sinais ${ }^{3,4,5}$.

Diferenças básicas entre a libras e a língua portuguesa podem ser evidenciadas pelo fato de a primeira ser visual-espacial, com sintaxe espacial, estrutura tópico-comentário, sem flexão de gênero, escrita não alfabética. Já a segunda é oral-auditiva, com sintaxe linear e escrita alfabética. Dessa forma, as expressões utilizadas na língua de sinais não são ditas usando o mesmo tipo de construção gramatical da língua portuguesa $^{3,5}$. A construção das expressões reflete a forma como o surdo processa suas ideias com base na sua percepção visual e espacial da realidade.

Como as línguas orais, a libras também está sujeita a variações regionais (sinais diferentes em cada região podem ter o mesmo significado), variações sociais (variação na configuração das mãos e/ou movimento) e mudanças históricas (alteração dos sinais com o decorrer dos tempos), ratificando o seu papel de língua natural e sua independência com relação à língua portuguesa ${ }^{5}$.

\section{LEGISLAÇÃO ESPECÍFICA: A SAÚDE E O SURDO - DECRETO DE LEI 5.626/2005}

O reconhecimento legal de sua utilização e composição foram sacramentados pela Lei $\mathrm{n}^{\mathrm{o}}$ 10.436/2002, regulamentada pelo Decreto $n^{\mathrm{o}} 5.626 / 2005$. A partir desse marco, a libras tornou-se língua oficial do Brasil, língua materna da comunidade surda brasileira, que deve ter garantido seu direito de uso e de sua difusão.

A legislação específica teve impactos em vários espaços sociais, principalmente na educação, que deve garantir o direito à educação da pessoa surda ou com deficiência auditiva por meio das medidas adotadas para incluir o ensino da libras como disciplina curricular em todas as graduações de licenciatura, fonoaudiologia e ensino especial; fomentar a formação de intérpretes e tradutores de libras; e estabelecer o papel do poder público e das empresas que detêm concessão ou permissão de serviços públicos, para o apoio ao uso e difusão da libras.

Dentre as implicações para a saúde, têm-se: a garantia do acesso das pessoas surdas ou com deficiência auditiva a um ambiente preventivo, curativo e reabilitador; programas de saúde destinados a tais utentes; e apoio à capacitação e forma- 
ção de profissionais da rede de serviços do sistema único de saúde (SUS) para o uso de libras. O inciso X, do artigo $25^{\circ}$ do Decreto 5.626 de 2005, garante o "apoio à capacitação e formação de profissionais da rede de serviços do SUS para o uso de libras e sua tradução e interpretação".

O Ministério da Saúde, atento às adaptações ao SUS, lançou os documentos A pessoa com deficiência e o Sistema Único de Saúde e Manual de legislação em saúde da pessoa com deficiência e diversas portarias sobre o assunto, com o intuito de fomentar em seus profissionais a inclusão social dessa parcela da população, com uma assistência específica à sua condição, além dos serviços prestados comumente aos demais cidadãos ${ }^{14,20}$.

Dez anos após a publicação da lei que regulamentou a libras no país, muitos desafios ainda precisam ser superados para que a comunidade surda tenha seus direitos preservados, principalmente porque o exercício de sua cidadania envolve a colaboração dos diferentes atores sociais, como a interação médico-paciente e o acesso aos serviços de saúde, perpassando pelos seus diferentes profissionais.

As barreiras de comunicação existentes entre profissionais da saúde e pacientes surdos podem pôr em risco a qualidade da assistência ofertada ${ }^{18,21}$. Associa-se a isso o fato de a legislação exigir profissionais habilitados ao atendimento ao paciente surdo. A adequação do currículo das escolas superiores de ciências da saúde, para contemplar as habilidades necessárias ao acolhimento desses pacientes, faz-se urgente.

Logo, verifica-se a importância da difusão dos conhecimentos sobre libras aos futuros profissionais da saúde do país, com vistas ao atendimento adequado, estabelecimento de vínculo e maior resolutividade dos problemas vivenciados pelas pessoas surdas. É preciso fazer com que as dificuldades representadas por medo, desconfiança e frustração, promotoras do uso diferente do sistema de saúde entre pacientes surdos e ouvintes, sejam minoradas ${ }^{18}$.

\section{COMUNIDADE SURDA NO TOCANTINS}

O estudo do processo de formação da comunidade surda na cidade de Palmas é escasso, talvez pela juventude da cidade, que conta apenas com 23 anos. Entretanto, reflexões críticas sobre as políticas sociais assumidas pelo Estado já são relatadas em pesquisas como a do sociólogo Ottmar Teske que, durante o período de 1995 a 1997, analisou aspectos da experiência vivida e compartilhada pelos surdos da cidade.

Em seu estudo, o pesquisador aponta a falta de informação dos surdos sobre seus direitos; os olhares estereotipados, exclusão já instalada socialmente; e a falta de harmonia na comunicação entre os próprios surdos ${ }^{22}$.
Outro estudo realizado entre os instrutores de libras de Palmas, TO, evidencia que há necessidade de conhecimento da variedade padrão da língua de sinais pelos surdos tocantinenses e escassez de formação de nível superior para os instrutores surdos com repercussões na qualidade do ensino e no desempenho dos candidatos tocantinenses na prova do PROLIBRAS, programa que oferece certificação aos profissionais que trabalham no ensino da língua, para atuar como instrutores e intérpretes ${ }^{23}$.

Essa realidade está em constante transformação e percebe-se maior movimentação da comunidade surda em prol de melhorias no ensino e do exercício de seus direitos. Manifestações públicas, organização de uma associação de surdos e o envolvimento de parcerias no ensino de libras são algumas das ações que atualmente fazem parte da realidade local.

A Universidade Federal do Tocantins (UFT) oferece à comunidade o curso básico de libras, por intermédio do Núcleo de Inclusão e Acessibilidade do Deficiente (Niad), com o intuito de fomentar o estudo da língua entre os acadêmicos, funcionários, familiares de surdos e público em geral. Da mesma forma, contribuem as entidades Fundação Universidade do Tocantins (Unitins), o Centro de Capacitação de Profissionais da Educação e de Atendimento às Pessoas com Surdez (CAS) e o Centro Universitário Luterano de Palmas (CEULP/ULBRA). No Brasil, a Federação Nacional de Educação e Integração dos Surdos (Feneis) é a entidade que tem por objetivo a defesa e a luta dos direitos da comunidade surda e tem como maior propósito a divulgação da libras ${ }^{2,24}$.

\section{RESULTADOS E DISCUSSÕES}

Os participantes do minicurso relataram que lhes foram proporcionados saberes que lhes permitirão estabelecer adequadas relações médico-paciente entre eles e os surdos. Despertou-se nos alunos o desejo de ampliar seus conhecimentos sobre a língua, capacitando-os a atuarem como facilitadores do acesso dos surdos aos serviços de saúde, contribuindo para a garantia de seus direitos como cidadãos.

Ofertou-se aos discentes a oportunidade de adquirir os conhecimentos mínimos sobre a libras, qualificando a atuação profissional para que o contato com os pacientes surdos seja uma demonstração de inclusão social.

O pré-teste evidenciou o desconhecimento dos alunos sobre a cultura surda e a linguagem de sinais, que referiram como mímica e/ou gestos sem muito valor para a comunicação. Os surdos foram identificados genericamente como os portadores de deficiência auditiva por todos os participantes.

No pós-teste, a mudança foi significativa: os alunos conseguiram diferenciar o surdo do portador de deficiência au- 
ditiva pela inserção ou não na cultura surda; destacaram a dificuldade dos surdos em aprender a língua oral por terem a língua de sinais como primeira língua e que a construção do conhecimento se faz de maneira diversa para cada uma das modalidades de linguagem; destacaram a dificuldade de comunicação encontrada tanto pelo paciente quanto para o profissional que desconhece grande parte dos temas abordados no minicurso; relataram que apesar de não reconhecerem todos os sinais da libras, já podem compreender melhor a necessidade do paciente surdo por meio dos componentes não manuais da língua de sinais; compreenderam que devem singularizar o processo terapêutico desses indivíduos, ultrapassando o modelo biomédico vigente e valorizar as diferentes nuanças que compõem esses pacientes (biopsicossocial e cultural); e enfatizaram a necessidade de proporcionar aos futuros profissionais de saúde noções elementares sobre língua de sinais.

As avaliações concordaram com a literatura, que afirma que o problema de comunicação do indivíduo surdo não é orgânico, e sim social e cultural ${ }^{21}$, pelo fato de a sociedade ouvinte não estar preparada para lidar com os surdos e, assim, atender adequadamente suas demandas.

Dessa forma, conseguiu-se atingir os objetivos propostos na elaboração do minicurso por ter despertado nos participantes o desejo de ampliar os conhecimentos sobre a libras e contribuir para minimizar a desinformação provocada pelas barreiras linguística e cultural existentes entre ouvintes e surdos.

\section{CONSIDERAÇÕES FINAIS}

O minicurso ministrado transpôs barreiras no ensino curricular dos alunos participantes e proporcionou ampliação do conhecimento sobre a temática. A relevância social do projeto deu-se em âmbito acadêmico e social por contribuir para a formação dos alunos; facultar a oportunidade de obtenção de novos conhecimentos; suscitar reflexões por parte dos discentes sobre a cultura surda, favorecendo a inclusão destes; e destruir estigmas e preconceitos sobre a comunidade surda.

Conforme elucidado, a libras é a língua pela qual o surdo se expressa, e os profissionais da saúde necessitam estudá-la. Para tanto, considera-se importante a produção de um manual prático com sinais do contexto da saúde, a fim de sistematizar e facilitar a qualificação dos diversos profissionais dessa área, o que representaria grande conquista para a difusão da libras no processo de cuidado.

A conquista de uma prática em saúde inclusiva em relação à pessoa surda será alcançada quando noções básicas sobre língua de sinais e particularidades culturais e linguísticas da comunidade surda forem considerados conhecimentos in- dispensáveis que devem ser ministrados ainda no transcorrer da formação acadêmica dos profissionais. Dessa forma, as habilidades comunicativas necessárias à satisfatória assistência a essa população serão desenvolvidas e praticadas.

\section{REFERÊNCIAS}

1. Oliveira GM. Brasileiro fala português: monolinguismo e Preconceito Lingüístico. Linguasagem [periódico na internet]. 2009 [acesso em 27 nov. 2012];11(12): 1-9. Disponível em: http:/ /www.letras.ufscar.br/linguasagem/edicao11/ artigo12.pdf

2. Felipe TA. LIBRAS em contexto: curso básico. Livro do estudante. 9aㅡ ed. Rio de Janeiro: WalPrint; 2009.

3. Quadros RM. O tradutor e intérprete de língua brasileira de sinais e língua portuguesa[online].Brasília: MEC; SEESP; 2004 [acesso em 27 nov. 2012]. Disponível em: http:/ / portal.mec.gov.br/seesp/arquivos/pdf/tradutorlibras. pdf

4. Quadros RM, Kanopp LB. Língua de sinais brasileira: estudos linguísticos. Porto Alegre: Artmed; 2004.

5. Paraná. Secretaria de Estado da Educação. Superintendência de Educação. Departamento de Educação Especial. Aspectos linguísticos da língua brasileira de sinais. Curitiba: SEED/SUED/DEE; 1998.

6. Brasil. Lei $\mathrm{n}^{\mathrm{o}}$ 10.436, de 24 de abril de 2002. Dispõe sobre a Língua Brasileira de Sinais - Libras - e dá outras providências [online]. Diário Oficial da República Federativa do Brasil. Brasília, 24 abr. 2002.[acesso em 20 jul. 2012]. Disponível em: http://www.planalto.gov.br/ccivil_03/ Leis/2002/L10436.htm

7. Brasil. Decreto $\mathrm{n}^{-}$5.626, de 22 de dezembro de 2005 . Regulamenta a Lei oㅗ 10.436, de 24 de abril de 2002, que dispõe sobre a Língua Brasileira de Sinais - Libras, e o art. 18 da Lei $\mathrm{n}^{\mathbf{0}}$ 10.098, de 19 de dezembro de 2000 [online]. Diário Oficial da República Federativa do Brasil. Brasília, 23 dez. 2005. [acesso em 20 jul. 2012]. Disponível em: http:/ / www.planalto.gov.br/ccivil_03/_ato2004-2006/2005/decreto/d5626.htm

8. Instituto Brasileiro de Geografia e Estatística.. Censo Demográfico Brasileiro 2000 [online]. [acesso em 15 jul. 2012]. Disponível em: http://www.ibge.gov.br/home/ estatistica/populacao/censo2000/populacao/deficiencia_Censo2000.pdf

9. Instituto Brasileiro de Geografia e Estatística. Censo Demográfico Brasileiro 2010 [online]. [acesso em 15 jul. 2012]. Disponível em: ftp://ftp.ibge.gov.br/Censos/Censo_Demografico_2010/Caracteristicas_Gerais_Religiao_Deficiencia/tab1_3.pdf 
10. Universidade Federal do Tocantins. Pró-Reitoria de Extensão, Cultura e Assuntos Comunitários - PROEX. Edital no 21 de 01 de setembro de 2010 [online]. Palmas; 2010. [acesso em 19 out. 2012]. Disponível em:http://sigproj1.mec. gov.br/edital_blank.php?id=325

11. Surdez. Disciplina de Otorrinolaringologia da Faculdade de Medicina da USP. [acesso em jun. 2012]. Disponível em: http:/ / www.surdez.org.br/surdez.asp e

12. Brasil. Ministério da Educação. Secretaria de Educação Especial. Saberes e práticas da inclusão: desenvolvendo competências para o atendimento às necessidades educacionais especiais de alunos surdos [online]. 2ª ed. Brasília: MEC; Secretaria de Educação Especial; 2006. 116 p. (Série: Saberes e práticas da inclusão).[acesso em jun. 2012]. Disponível em: http://portal.mec.gov.br/seesp/arquivos/ pdf/alunossurdos.pdf

13. Barnett S. Communication with deaf and hard-of-hearing people: a guide for medical education. Acad Med. 2002;77(7).

14. Brasil. Ministério da Saúde. Secretaria de Atenção à Saúde. Departamento de Ações Programáticas Estratégicas. A pessoa com deficiência e o Sistema Único de Saúde [online]. 2 $2^{\underline{a}}$ ed. Brasília: MS;2007. [acesso em 5 fev. 2012]. Disponível em:http://bvsms.saude.gov.br/bvs/ publicacoes/07_0327_M.pdf

15. SÁ NL. Cultura, poder e educação de surdos. São Paulo: Paulinas; 2006.

16. Strobel K. As imagens do outro sobre a cultura surda. Florianópolis; 2008.

17. Strobel K. As imagens do outro sobre a cultura surda. Florianópolis: UFSC; 2008.

18. Chaveiro N, Porto CC, Barbosa MA. Relação do paciente surdo com o médico.Rev Bras Otorrinolaringol [periódico na internet].2009 [acesso em 3 fev. 2012]; . 75(1):147-50. Disponível em: http://www.scielo.br/pdf/rboto/v75n1/ v75n1a23.pdf

19. Stokoe WC. A dictionary of American Sign Language on linguistic principles. Silver Spring, Md: Linstok Press; 1976.

20. Brasil. Ministério da Saúde. Secretaria de Atenção à Saúde. Departamento de Ações Programáticas Estratégicas. Manual de legislação em saúde da pessoa com deficiência [online] 2 $2^{\underline{a}}$ ed. rev. atual. Brasília: MS;2006. [acesso em 19 out. 2012]. Disponível em http://bvsms.saude.gov.br/ bvs/publicacoes/legislacao_deficiencia.pdf
21. Chaveiro N, Barbosa MA, Porto CC.Revisão de literatura sobre o atendimento ao paciente surdo pelos profissionais da saúde. Rev Esc Enferm USP [periódico na internet]. 2008 [acesso em 3 fev. 2012]; .42(3):578-83.Disponível em:http:/ / www.scielo.br/pdf/reeusp/v42n3/v42n3a22.pdf

22. Teske O. A surdez, os surdos e as relações de poder(es): um olhar sobre o processo de formação das comunidades surdas. In: Anais do Seminário Surdez, cidadania e educação: refletindo sobre os processos de exclusão e inclusão. Rio de Janeiro: INES, Divisão de estudos e Pesquisas, 1998.

23. Bueres TCHK. Um estudo sobre a formação linguística dos instrutores de libras em Palmas -Tocantins [online]. João Pessoa; 2010. Mestrado [Dissertação] - Universidade Federal da Paraíba. Programa de pós-graduação em linguística, 2010.[acesso em 3 fev. 2012]. Disponível em: http:/ / www. cchla.ufpb.br/proling/index.php/produ-cientca-mainmenu-80/33-dissertacoes/355-um-estudo-sobre-a-formacao-linguistica-dos-instrutores-de-libras-em-palmas-tocantins

24. Federação Nacional de Educação e Integração dos Surdos. Libras: língua brasileira de sinais [online]. [acesso em 15 jun. 2012]. Disponível em: http://www.feneis.org.br/ page/feneis.asp

\section{CONTRIBUIÇÃO DOS AUTORES}

Danielle de Azevedo Levino participou da redação, tradução e participação no minicurso. Emyle Brito de Souza, redação, revisão e participação no minicurso. Pedro Capela Cardoso, redação, revisão geral. Anderson Carvalho da Silva, redação, revisão, participação no minicurso e orientação. Adriana Edelves Trindade Martins Carvalho contribuiu na participação no minicurso e orientação.

\section{CONFLITO DE INTERESSES}

Declarou não haver.

\section{ENDEREÇO PARA CORREPONDÊNCIA}

Danielle de Azevedo Levino

Colônia Agrícola Samambaia,chácara 49,lote 2

Taguatinga

CEP 72110-600 DF.

E-mail: dani.levino@gmail.com. 